\title{
Effect of cyclosporin A on the survival of corneal grafts in rabbits
}

\author{
W. F. I. SHEPHERD, D. J. COSTER, T. CHIN FOOK, \\ N. S. C. RICE, AND B. R. JONES \\ From the Pocklington Eye Transplantation Research Unit, Department of Clinical Ophthalmology, \\ Institute of Ophthalmology, and Moorfields Eye Hospital, City Road, London ECIV 2PD
}

SUMMARY Cyclosporin A given to rabbits intramuscularly in a dose of $25 \mathrm{mg} / \mathrm{kg} / \mathrm{day}$ for up to 28 days after corneal transfer results in a marked prolongation in the survival of penetrating corneal grafts compared to that in an untreated control group. Cyclosporin A $1 \%$ drops did not prolong survival of the corneal graft, but this may be related to the need for skin transfer 14 days after corneal transfer to ensure rejection, and supports the idea that the drug plays an immunosuppressive role at the time and place of sensitisation.

The fungal metabolite, cyclosporin $\mathrm{A}$, which has potent antilymphocytic activity and little toxicity in mice, rats, rabbits, dogs, and pigs, has been shown to prolong survival of a wide range of allografts in animals and man. ${ }^{1}$ It offers an outstanding prospect for effective suppression of the allograft response, a major obstacle to progress in transplantation surgery.

Advances in microsurgery and increasing awareness of the role of the endothelium and the importance of its preservation have highlighted rejection as the major obstacle to successful corneal transplantation. Allografts in vascularised corneas are associated with much higher rates of rejection than those in avascular corneas. ${ }^{2}$ The prognosis for corneal grafts correlates also with immunological parameters such as the degree of histocompatability $^{2}$ and the presence of cytotoxic antibodies prior to surgery. ${ }^{3}$ Tissue matching, although useful in high risk patients, is not a practical solution to the problem at present. The future of corneal grafting in high-risk patients is related to the development of effective immunosuppression without the complications of conventional regimens.

The behaviour of allografts varies considerably with different tissues and from species to species. It is necessary to examine a prospective immunosuppressive treatment in precisely the situation for which it is intended. The purpose of this study has

Correspondence to D. J. Coster, Department of Clinical Ophthalmology, Moorfields Eye Hospital, City Road, London ECIV 2PD. been to examine the effect of cyclosporin $A$ on the survival of corneal grafts. Penetrating corneal grafts in rabbits provide the opportunity for preliminary investigations.

In contrast to skin and other allografts, in which the mean survival time is short and reproducible, grafts performed into healthy avascular corneas enjoy prolonged survival, and only a very small percentage undergo graft rejection. To ensure rejection of corneal allografts in rabbits, it is necessary to induce vascularisation of the graft and transfer skin to ensure sensitisation.

\section{Materials and methods}

The experiments involved the transfer of corneas between rabbits from different breeding stock, followed by exchange of skin grafts between the same pairs 14 days later.

\section{ANIMALS}

Pairs of outbred Dutch rabbits (weight 1-2 kg) from 2 different sources (Hyline and Gareside) were used to ensure grafts were exchanged between unrelated animals.

\section{OPERATIVE PROCEDURE}

Corneal transfer. $6 \mathrm{~mm}$ penetrating grafts were exchanged between pairs.

After induction of anaesthesia full mydriasis was obtained with phenylephrine $10 \%$ and atropine $1 \%$. In addition each rabbit received 5000 units of 

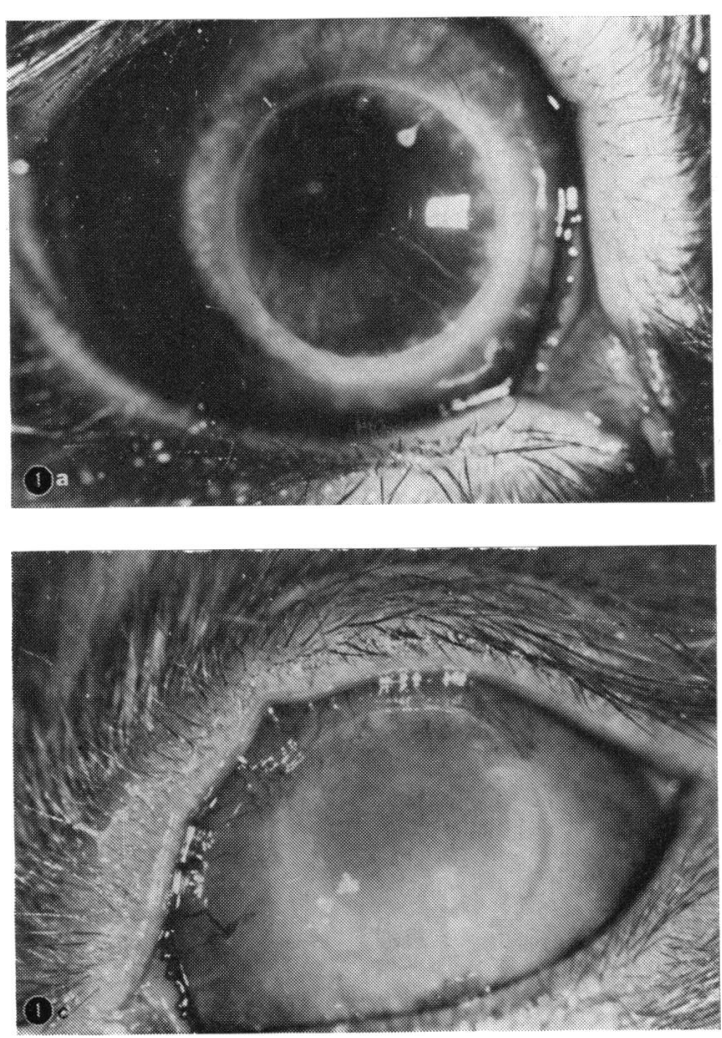

heparin intravenously to prevent aqueous clotting during the operation. The eyelashes were cut and superior and inferior rectus sutures inserted to improve corneal exposure and stabilise the globe. $6 \mathrm{~mm}$ discs were trephined, the excision of the disc being completed with corneal scissors. The exchanged discs were fixed with 4 stay sutures of $10 / 0$ monofilament nylon and a continuous $10 / 0$ monofilament nylon suture was inserted. The stay sutures were removed before tightening the continuous suture, the knot of which was left exposed to stimulate vascularisation. The anterior chamber reformed spontaneously, but if any synechiae to the interface were present air was injected via a limbal paracentesis.

Corneal sutures were removed on day 14 at the slit-lamp under topical anaesthesia.

Skin transfer. Circular full-thickness skin grafts of $12 \mathrm{~mm}$ diameter were exchanged between pairs 14 days after the corneal graft. Only rabbits with corneal grafts which were clear and uncomplicated received skin grafts and were included in the study. Each graft was soaked in penicillin/streptomycin solution before being sutured in place with eight interrupted $7 / 0$ silk sutures and then covered with an antibiotic spray.

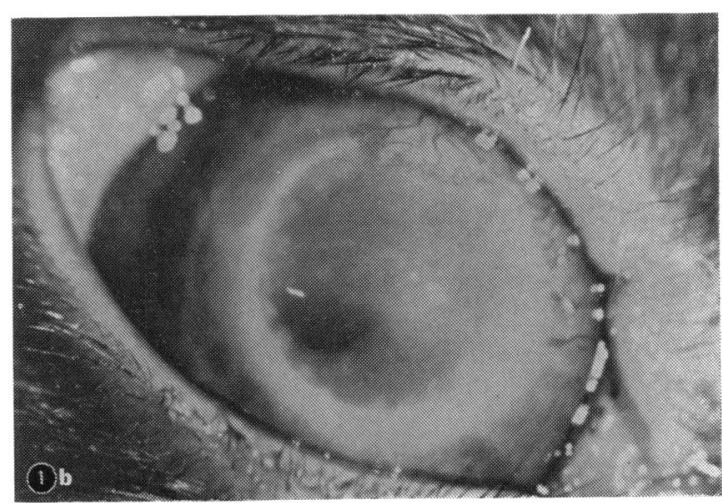

Fig. 1 The characteristic appearance of corneal graft rejection in the rabbit. (a) Clear corneal graft. (b) Commencement of rejection with an anterior chamber inflammatory reaction, epithelial and endothelial rejection line. (c) Within 5 days the cornea is thickened, oedematous, and opaque.

\section{ANAESTHESIA}

Corneal and skin grafts were done under general anaesthetic.

Animals were anaesthetised with lignocaine through an indwelling venous catheter to facilitate the maintenance of anaesthesia. This was supplemented by topical anaesthesia (proparacaine $0.5 \%$ ) for the cornea and by infiltrating the skin with $2 \%$ xylocaine and adrenaline $1 / 80000$ prior to skin grafting.

\section{EVALUATION}

Cornea. Mydriasis was maintained for 1 week. The animals were examined daily by slit-lamp biomicroscopy for graft clarity, iritis, and corneal vascularisation and scored accordingly. A diagnosis of corneal graft rejection was made when a previously clear graft in a noninflamed eye developed an inflammatory reaction with or without an epithelial or endothelial rejection line and then progressed to endothelial decompensation and corneal opacification (Fig. 1). The time to rejection was taken as the time from corneal grafting to the initiation of these events.

Skin. The progress of the skin graft was examined daily, and the softness, pliability, colour, and 


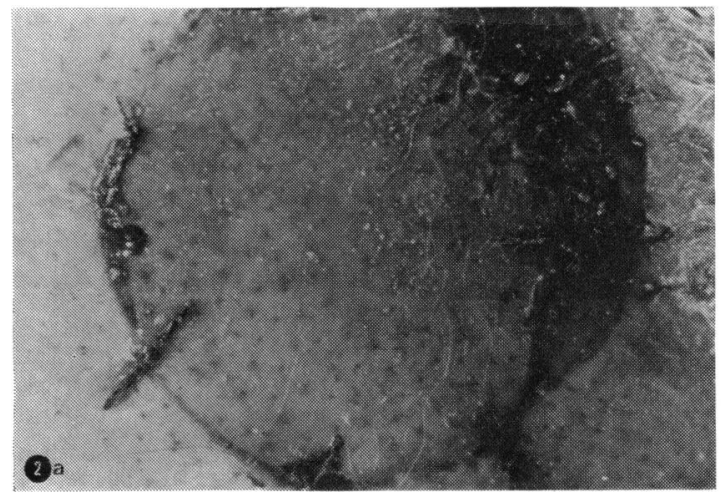

Fig. 2 Skin graft rejection in the rabbit. (a) Viable skin grafted 6 days previously. (b) Commencement of rejection with necrosis of the edge of the graft and general thickening and an associated loss of pliability. (c) Within 3 days the graft epithelium is totally necrotic.

viability were recorded. The time to rejection was taken as the time from skin grafting to the point at which $50 \%$ of the previously viable epithelium was necrosed (Fig. 2).

\section{TREATMENT}

Animals were allocated to 1 of 5 treatment groups; 1 was a control group, 3 received intramuscular cyclosporin $A$, and 1 received cyclosporin $A$ in drop form. The details of the treatment schedules are displayed in Table 1. Animals receiving intramuscular cyclosporin A were given $25 \mathrm{mg} / \mathrm{kg}$ per

Table 1 Experimental groups

\begin{tabular}{|c|c|c|c|}
\hline & $\begin{array}{l}\text { Number of } \\
\text { animals }\end{array}$ & $\begin{array}{l}\text { Treatment } \\
\text { schedule }\end{array}$ & \\
\hline Group I & 10 & Nil-control & \\
\hline Group II & 10 & $\begin{array}{l}\text { Cyclosporin A } \\
25 \mathrm{mg} / \mathrm{kg} / \text { day }\end{array}$ & Day 0-day 28 \\
\hline Group III & 8 & " & Day 0-day 14 \\
\hline Group IV & 11 & ", & Day $14-$ day 28 \\
\hline Group V & 7 & $\begin{array}{l}\text { Cyclosporin A } 1 \% \\
\text { eye drops } 5 \text { times } \\
\text { per day }\end{array}$ & Day 0-day 28 \\
\hline
\end{tabular}
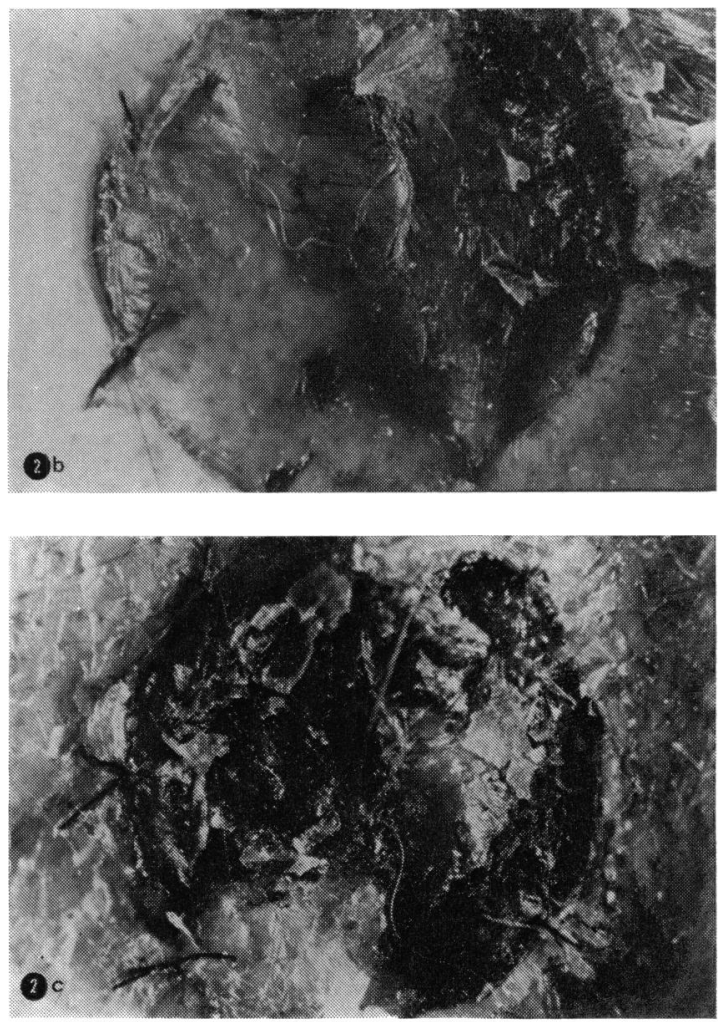

day. Drops were prepared as $1 \%$ solution in arachis oil and were given 5 times a day for 28 days.

\section{Results}

The results are displayed in Figs. 3-7.

GROUP I

All the animals in the control group rejected their grafts promptly. No corneal rejection was observed prior to skin transfer, but $50 \%$ were rejected within 3 weeks of skin transfer, that is, 5 weeks after corneal surgery. One cornea survived 10 weeks after corneal transfer before being rejected, but this was in an eye which had failed to vascularise.

Skin rejection in this control group occurred early. More than $50 \%$ were rejected within a week of skin transfer, and all rabbits rejected skin within 2 weeks.

GROUP II

Animals treated with cyclosporin A $25 \mathrm{mg} / \mathrm{kg}$ per day intramuscularly for 28 days from the time of corneal grafting showed prolonged graft survival. The extent of this prolongation of corneal survival 
compared to the control group is set out in Fig. 3, and the prolonged survival of skin grafts is displayed in Fig. 4.

Corneal graft survival was prolonged to the extent that $50 \%$ of grafts remained clear 14 weeks after corneal transfer, and 1 graft survived indefinitely. Skin graft survival was also prolonged with $50 \%$ of grafts surviving 3 weeks after skin transfer, with 1 graft surviving indefinitely.

\section{GROUP III}

A shorter period of administration of cyclosporin A for 14 days from the day of corneal transfer also resulted in prolonged corneal graft survival. 50\%

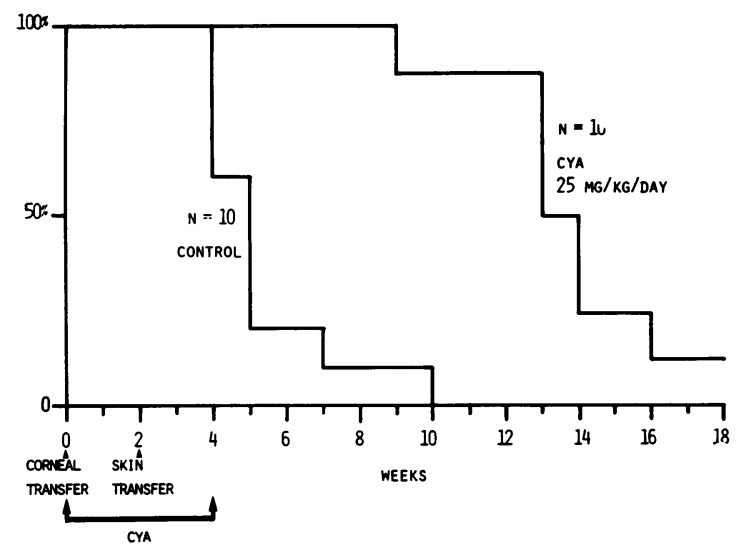

Fig. 3 Survival graph comparing the effect on corneal graft survival of cyclosporin $\mathrm{A}, 25 \mathrm{mg} / \mathrm{kg} /$ day, intramuscularly for 28 days from the time of corneal transfer.

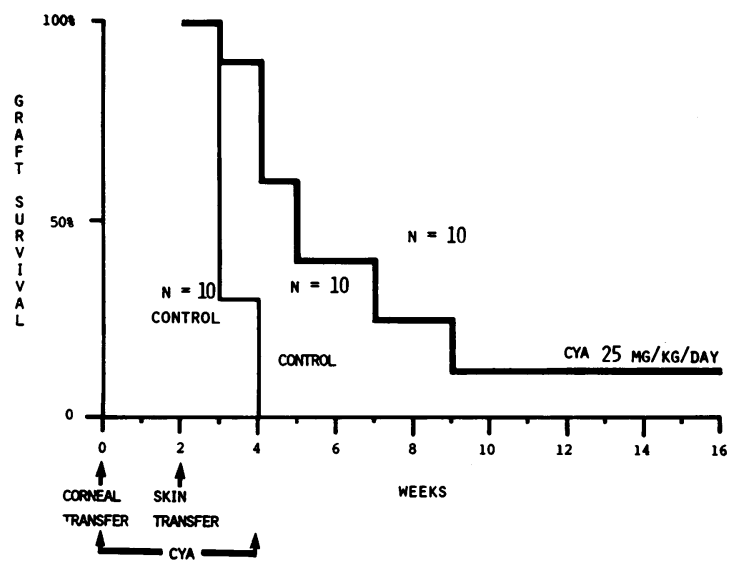

Fig. 4 Survival graph comparing the effect on skin graft survival of cyclosporin $\mathrm{A}, 25 \mathrm{mg} / \mathrm{kg} /$ day, intramuscularly for 28 days from the time of corneal transfer.

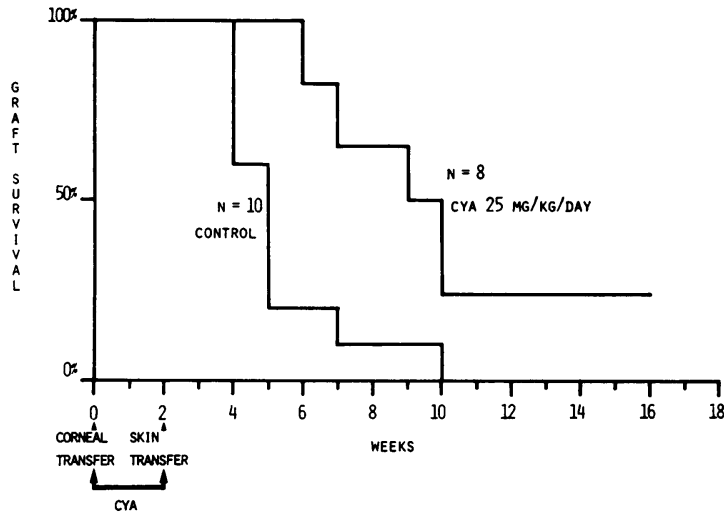

Fig. 5 Survival graph comparing the effect on corneal graft survival of cyclosporin A, $25 \mathrm{mg} / \mathrm{kg} /$ day, intramuscularly for 14 days from the time of corneal transfer.

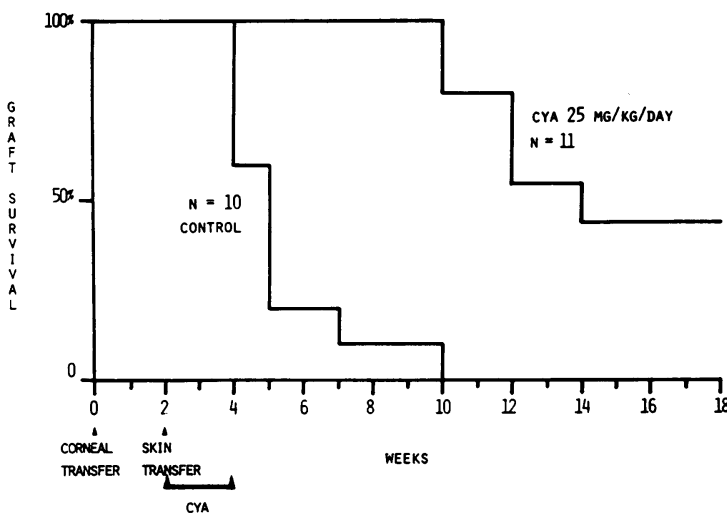

Fig. 6 Survival graph comparing the effect on corneal graft survival of cyclosporin $\mathrm{A}, 25 \mathrm{mg} / \mathrm{kg} /$ day, intramuscularly for 14 days from the time of skin transfer, that is, commencing 14 days after corneal transfer.

of grafts survived 10 weeks, and there were 2 indefinite survivors (Fig. 5).

GROUP IV

The administration of cyclosporin A for 14 days after skin transfer was also associated with prolonged corneal graft survival. $50 \%$ of corneas remained clear for 14 weeks after corneal transfer. There were 3 indefinite survivors (Fig. 6).

GROUP V

Topical cyclosporin A $1.0 \%$ eye drops given 5 times a day for 28 days from the day of corneal transfer did not influence the survival of corneal grafts (Fig. 7). 
Fig. 7 Survival graph comparing the effect on corneal graft survival of cyclosporin $A, 1.0 \%$ eye drops, given 5 times a day for 28 days from the time of corneal transfer.

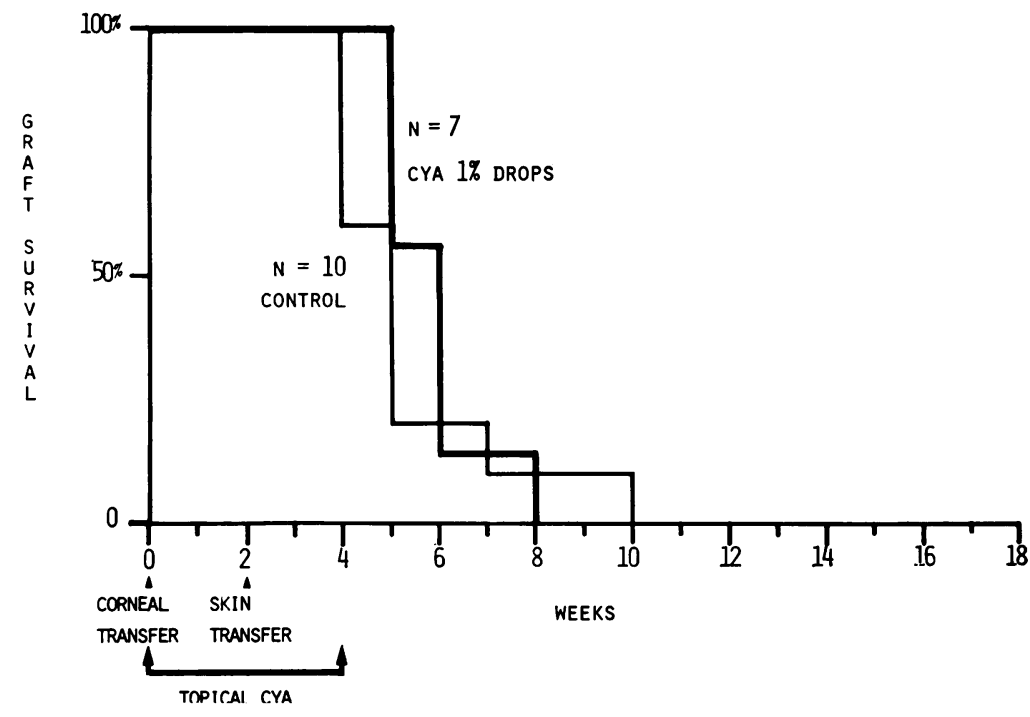

\section{Discussion}

Parenteral cyclosporin A markedly prolongs the survival of corneal grafts in rabbits. These experiments demonstrate several features of this drug, in particular the way in which allograft survival is increased after only short-term therapy and the way in which a proportion of grafts remain unrejected for a very long time.

The results are in accord with those of other workers using different animals and grafting a wide range of tissues. Survival of bone marrow, kidney, liver, and heart grafts in rats, rabbits, pigs, and dogs as well as heart grafts in nonhuman primates $^{4-12}$ have been markedly prolonged and encourage the use of cyclosporin A in clinical practice. Clinical experience so far is restricted to a small number of centres involved in essential organ grafting. In terms of graft survival and prevention of graft-versus-host disease in bone marrow recipients, the clinical use of this drug has been most encouraging. ${ }^{13}{ }^{14}$ Two major difficulties have arisen. Although cyclosporin $\mathrm{A}$ is not myelotoxic to any degree, changes do occur in the liver and kidney related to its administration, but what is more worrying is the high incidence of lymphoma in the small number of patients receiving the drug. ${ }^{1}$

No substantial degree of systemic toxicity is justifiable with a drug used to protect grafts in nonessential organs such as the cornea. Since it is unlikely that immunosuppression without complications can be achieved with a systemic drug, the future of corneal grafting is very much related to the development of immunosuppressive agents that can be effectively delivered topically.
Failure of topically applied cyclosporin $\mathrm{A}$ in these experiments may be related to the model. It has been clearly shown that cyclosporin $\mathrm{A}$ is more likely to be effective when it is delivered with an antigen. Failure of the drug when it is applied directly to the eye is not surprising in a model in which remote skin grafts provide the sensitisation necessary to initiate corneal graft rejection. An encouraging feature was the way in which the rabbits tolerated the topical preparation; there was no untoward reaction apparent in the cornea or conjunctiva, but there was an initial loss of hair from the eyelids. Clearly different models are needed to assess the potential for topical treatment of this drug, and these studies are being pursued. The unique specifity and low toxicity of cyclosporin A suggest that this class of drug is more likely to offer a solution to the problem of corneal graft rejection than any agent yet tested.

We thank Dr J. F. Borel of Sandoz Ltd., Basle, for supplying the cyclosporin $\mathrm{A}$ and for his invaluable advice.

\section{References}

${ }^{1}$ Editorial. Cyclosporin A. Lancet 1979; 2: 779-80.

${ }^{2}$ Batchelor JR, Casey TA, Gibbs DC, et al. HLA matching and corneal grafting. Lancet $1976 ; 1: 551-4$.

${ }^{3}$ Stark WJ, Taylor HR, Bias W, Maumenee E. Histocompatability (HLA) antigens and keratoplasty. Am J Ophthalmol 1978; 86: 595-604.

${ }^{4}$ Borel JF, Feurer C, Magnée C, Stähelen H. Effects of the new anti-lymphocyte peptide Cyclosporin $\mathrm{A}$ in animals. Immunology 1977; 32: 1017-25.

${ }^{5}$ Dunn DC, White DJG, Wade J. Survival of first and second kidney allografts after withdrawal of cyclosporin A therapy. Int Res Commun Ser Med Sci 1978; 6: 464. 
${ }^{6}$ Green CJ, Allison AC. Extensive prolongation of rabbit kidney allograft survival after short-term cyclosporin A treatment. Lancet $1978 ; 1: 1182-3$.

${ }^{7}$ Green CJ, Allison AC, Precious S. Induction of specific tolerance in rabbits by kidney allografting and short periods of cyclosporin A treatment. Lancet 1979; 2: 123-5.

${ }^{8}$ Calne RY, White DJG, Rolles K, Smith DF, Herbertson BM. Prolonged survival of pig orthotopic heart grafts treated with cyclosporin A. Lancet 1978; 1 : 1183-5.

${ }^{9}$ Tutschka PJ, Beschomer WE, Allison AC, Burns WH, Santos GN. Use of cyclosporin A in allogeneic bone marrow transplantation in the rat. Nature $1979 ; 280$ : 148-51.

${ }^{10}$ Calne RY, White DJG. Cyclosporin A-a powerful immunosuppressent in dogs with renal grafts. Int Res Commun Ser Med Sci 1977; 5: 595.

${ }^{11}$ Jamieson SW, Burton NA, Bieber CP, et al. Cardiac allograft survival in primates treated with cyclosporin A. Lancet 1979; 1: 545.

${ }^{12}$ Kostakis AJ, White DJG, Calne RY. Prolongation of rat heart allograft survival by cyclosporin A. Int Res Commun Ser Med Sci 1977; 5: 280.

${ }^{13}$ Calne RY, White DJG, Thiru S, et al. Cyclosporin A in patients receiving renal allografts from cadaver doners. Lancet 1978; 2: 1323-6.

${ }^{14}$ Powles RL, Barrett AJ, Clink H, Kay HEM, Sloane J, McElwain TJ. Cyclosporin A for the treatment of graftvenous host disease in man. Lancet 1978; 2: 1327-30. 